\title{
Experiencia subjetiva del espacio urbano y alienación. Un análisis a partir de la generalización de los dispositivos de navegación digital
}

\author{
Subjective experience of urban spaces and alienation \\ considering the generalization of digital navigation devices
}

GONZALO VELASCO ARIAS (Universidad Carlos III de Madrid)

Artículo recibido: 4 de mayo de 2019

Solicitud de revisión: 16 de octubre de 2019

Artículo aceptado: 26 de febrero de 2020

Velasco, Gonzalo (2020). Experiencia subjetiva del espacio urbano y alienación. Un análisis a partir de la generalización de los dispositivos de navegación digital. Recerca. Revista de Pensament i Análisi, 25(2), pp. 31-54.

Resumen

La revisión de las humanidades a partir de la cultura material parte de la consideración de que la conciencia y la agencia humanas no pueden disociarse de su nicho tecnológico. El presente artículo trata de indagar cómo la experiencia subjetiva de la ciudad se ha visto modificada por la universalización del smartphone como herramienta de orientación a través de los sistemas de navegación GPS. Con este fin, y a través del marco teórico formulado por Henri Lefebvre, el artículo realiza un análisis exploratorio acerca de la producción del espacio urbano contemporáneo. Recurriendo a la revisión crítica de la teoría cartográfica, interroga si la universalización de los mapas digitales supone una recuperación de la experiencia subjetiva o una extensión del espacio abstracto propio del capitalismo de la experiencia.

Palabras clave: representación del espacio, prácticas espaciales, experiencia, flâneur, alienación, navegación digital.

Abstract

The new approach to Humanities based on material culture starts from the consideration that human conscience and agency cannot be dissociated from their technological niche. The present article aims to investigate how the subjective experience of the city has been changed by the generalization of the smartphone and GPS orientation. To this goal, and 
founding on Henri Lefebvre's theoretical framework, the article deploys an exploratory analysis about the production of contemporary urban space. Resorting to the critical review of the cartographic theory, the article asks whether the universalization of digital maps involves a recovery of subjective experience or an extension of the abstract space proper to the capitalism of experience.

Key Words: representational space, spatial practices, experience, digital navigation, flâneur, alienation.

\section{INTRODUCCIÓN: CULTURA MATERIAL Y PERCEPCIÓN DEL ESPACIO}

La filosofía ha negligido tradicionalmente su atención hacia los objetos. Aunque la dialéctica materialista naciera en buena medida para compensar la fundamentación subjetiva de toda consideración práctica y cognitiva, lo hizo atendiendo a estructuras objetivas en sí idealizadas, comprendidas a partir de su tradición conceptual. Es cierto que la comprensión especulativa de la relación entre sujeto y objeto asume la codeterminación entre la conciencia subjetiva y el entorno cultural y tecnológico (Torres-Albero, 2005), pero ha tendido a hacerlo en una escala abstracta que tiene como objeto definir las metamorfosis de la conciencia con alcance pretendidamente universal, relegando el análisis del condicionamiento concreto del entorno de objetos y artefactos a otras disciplinas.

La preocupación filosófica por nuestro entorno de objetos materiales tuvo que esperar a dos tradiciones de análisis diferentes, pero complementarias en su enfoque. Por un lado, la filosofía de la vida cotidiana reivindicada por pensadores franceses como Henri Lefebvre (1980) o Michel de Certeau (2007), como respuesta especulativa y metodológica a la politización de lo personal reivindicada por la revuelta contracultural de 1968. Por otro, ha sido cierta filosofía analítica de la agencia, con base en una filosofía de la técnica de alcance antropológico, la que está reivindicando una revisión materialista de la cultura y, con ello, del enfoque de las humanidades en su conjunto (Broncano, 2012).

Desde este último punto de vista, toda cultura es una cultura material, en el sentido de que tanto las estructuras de la conciencia como las posibilidades de la agencia están condicionadas por nuestras redes de artefactos y prácticas de uso (Broncano, 2018). Del mismo modo que un arco inaugura la posibilidad de cazar a distancia y permite la generación de todo un modo de habitar 
y convivir en torno a esa posibilidad, o al igual que la escritura funda la civilización por habilitar la transmisión del conocimiento y de la memoria compartida, también los artefactos de nuestra cotidianeidad fundan espacios de posibilidad para la agencia y el conocimiento (Broncano, 2010: 408). Al irse conformando redes de artefactos interdependientes entre sí y de las prácticas sociales que los convertían en significativos, se establecen espacios de posibilidad para la conciencia y la práctica, en los que a su vez se asientan los imaginarios, los relatos y las expectativas de cada momento y contexto histórico-social (Broncano, 2009).

La ciudad es el más denso nicho de artefactos de la acción humana. Si en el paradigma de la cultura material la dualidad entre sujeto y objeto tiende a disolverse en la idea de affordance —estructuras objetivas de posibilidad-, el espacio urbano debería ser un objeto de estudio principal para la indagación filosófico-antropológica. Desde este punto de vista, la ciudad es inherente a la naturaleza humana, en tanto que nicho tecnológico capaz de potenciar las posibilidades de la vida y convivencia humanas. Como sostiene David Harvey, la ciudad es un derecho fundamental que no debería ser alienado por los intereses especulativos del capital (Harvey, 2008a). Según este autor, la soberanía sobre el espacio urbano debería ser un derecho humano, en tanto que la inherencia de la técnica a nuestra condición torna imposible el retorno a lo natural, que aparece solo como objeto de una nostalgia compensatoria por los efectos enajenantes de la civilización (De Azúa, 2015). El estudio filosófico del espacio urbano como mediación entre las estructuras ideales de la civilización y las affordances técnicas que estructuran el ámbito de lo posible, por tanto, lejos de ser un interés sectorial, ha de entenderse como un elemento fundamental de la antropología filosófica.

La vivencia del espacio urbano, de este modo, adquiere una relevancia trascendental, en tanto que es la experiencia que media entre la realización de las determinaciones abstractas de nivel global y la posibilidad cotidiana de la vida concreta (Lefebvre, 2013). Esta es la concepción de la función del espacio urbano en la obra de Henri Lefebvre, que será detallada en el apartado subsiguiente. A su vez, no obstante, esta vivencia del espacio urbano está mediada por un nicho de artefactos que condicionan el desplazamiento, la orientación y su representación simbólica, siendo quizás los más destacables los medios de transporte públicos y privados y también los mapas.

Un mapa es un artefacto de carácter simbólico y representacional, pero es también, y sobre todo, un horizonte de posibilidades de movimiento en el espacio (Broncano, 2012: 107). Mapas y viajes hacen del entorno geográfico un 
espacio de direcciones y de metas y no simplemente de vagabundeos y nomadeos. La necesidad de un mapa en la ciudad es relativa a la habituación del espacio a través de la insistencia en el recorrido. El habitante de la ciudad recurre al callejero solo en la medida en que un desplazamiento se aleje de sus recorridos habituales, que, sin embargo, le permiten una orientación aproximada en relación con emplazamientos desconocidos. El mapa urbano, a su vez, convive singularmente con la representación sintética de los recorridos del transporte público: mapas del metro y de las redes de autobuses y cercanías que la atraviesan. En urbes de gran tamaño, estas últimas operan como vectores de dirección que amoldan la percepción del espacio urbano en su conjunto a la división de sus ejes.

La percepción del espacio urbano a través de la representación gráfica del mapa ha experimentado una revolución reciente, como consecuencia de la generalización de los dispositivos inteligentes y de la universalización de la conexión de alta velocidad. Según el informe del Pew Research Center publicado en el 2018, la media de individuos que declaraban tener un smartphone en los países de economías avanzadas era de un $76 \%$, mientras que un $17 \%$ declaraba poseer un móvil no inteligente y solo un 6 \% carece de teléfono móvil $^{1}$ (Pew Research Center, 2019). Como correlato de ese fenómeno, se hace habitual el manejo de mapas digitales en los que, gracias a las tecnologías de geolocalización, la representación objetiva del espacio se adapta a la posición del sujeto en tiempo real.

Partiendo de la universalización de esta tecnología, el presente artículo plantea las siguientes preguntas de investigación: ¿cómo ha modificado la percepción del espacio objetivo la generalización del acceso inmediato a la cartografía digital y a los sistemas de orientación GPS? ¿Podemos seguir hablando de un espacio urbano objetivo o, al contrario, las referencias compartida se diluyen en el acceso subjetivo a la orientación? ¿Cómo afecta a la construcción subjetiva de la vivencia urbana la incorporación de información relativa a servicios y experiencias en los mapas digitales?

La hipótesis que servirá de guía para tratar de responder a estos interrogantes es que, bajo la ilusión de una democrática interactividad en la definición experiencial del espacio, aplicaciones de orientación a tiempo real como Google Maps condicionan la autonomía de la experiencia urbana y colonizan el espacio de agencia subjetiva. La posibilidad de una apropiación vivencial y

Con un $95 \%$, Corea del Sur es el país con una tasa más alta de uso de smartphones. Le siguen Israel (88\%), Países Bajos (87\%), Suecia (86\%), Estados Unidos y Australia (81\%) y España (80 \%). 
estética del espacio urbano desaparece, colonizada por una homogeneización de la experiencia disfrazada de la aparente interactividad de los mapas virtuales.

\section{LA PRODUCCIÓN DEL ESPACIO SEGÚN HENRI LEFEBVRE}

Aunque la recepción posmoderna de Lefebvre ha interpretado su obra como una reflexión sectorial acerca del espacio, su aportación específica es la definición de lo urbano como un espacio de mediación entre la particularidad de la vida cotidiana y los fenómenos globales de la historia (Schmid, 2008: 2745).

En La revolución urbana (1972) distingue tres niveles de realidad: un aspecto global en el que adquiere su realidad más abstracta y universal (la del Estado y el capital); un aspecto cotidiano (que Lefebvre llama también «lo privado» o «el habitar», haciendo un uso un tanto laxo de la reminiscencia heideggeriana); y una manifestación urbano-espacial, que media entre la abstracción y la vivencia cotidiana. El nivel urbano mediador —en el que las racionalidades opuestas de lo global y lo cotidiano chocan- adquiere así una trascendencia política decisiva (Goonewardena, 2011: 13).

El interés de Lefebvre como marco teórico de una reflexión sobre el espacio urbano, por tanto, radica en su comprensión como nicho material que habilita posibilidades para la agencia, compenetrado a su vez con las estructuras globales y abstractas de las relaciones de producción y las instituciones de gobierno. Para Lefebvre, el espacio no es un mero contenedor neutral de la acción y la cultura humanas, sino el resultado de las relaciones de producción y de la acumulación de un proceso histórico en el que se entremezclan las representaciones objetivas del espacio, las prácticas espaciales que se dan en un determinado espacio y el imaginario simbólico y social que genera (Lefebvre, 2013). La representación del espacio -o espacio concebido en clave fenomenológica- es el representado y conceptualizado con afán de adecuación y correspondencia con la realidad del territorio, compuesto por un lenguaje propio de signos que requieren una codificación. El espacio de representación -o espacio vivido-, por su parte, remite a las expectativas simbólicas acerca de lo que debería ser el espacio. Por último, las prácticas espaciales -espacio percibido- es el experimentado por sus habitantes a través de hábitos cotidianos y rituales. La relación trialéctica entre estas tres esferas dificulta la legibilidad del espacio: para Lefebvre, no existe causalidad sino codeterminación 
simultánea entre todas ellas (Dear, 1994: 35). El individuo interioriza los valores y normas asociadas al espacio concebido y al espacio de representación, que actualiza de manera inconsciente mediante sus propias prácticas espaciales (Baringo Ezquerra, 2013: 126).

Enraizado en la tradición humanista del marxismo, para Lefebvre el riesgo de alienación en la ciudad se da cuando las representaciones del espacio subordinan las prácticas espaciales, con el objetivo de que estas no generen «resistencias ni obstáculos» a un espacio homogéneo y mercantilizado donde todos los elementos sean intercambiables (Lefebvre 1972: 293). En ese espacio abstracto de la ciudad capitalista contemporánea, las representaciones del espacio neutralizan las prácticas espaciales — relacionadas con la vivencia corporal del espacio- y su imaginario, de tal manera que la vivencia y la reinterpretación subjetiva del espacio no son un fin en sí mismo, sino un medio para la consecución de un objetivo abstracto, que Lefebvre identifica con la reproducción del capital (Dimendberg, 1998: 32). Resume bien esta idea el primer parágrafo de La sociedad del espectáculo de Guy Debord, escrito con ese mismo contexto histórico-cultural: «todo lo que en su día fue vivido se ha convertido en mera representación» (Debord, 2010: 7). En la misma línea se ha manifestado Paul Virilio, para quien la urbanización del espacio real ha sido sustituida por la urbanización del tiempo real (Virilio, 1997).

La hipótesis de investigación de este artículo es que la relación de poder específica de la experiencia actual de la ciudad no es la mera negación de la inmanencia por parte de un orden de representación abstracta, como podía sostener Lefebvre. En el régimen de producción del espacio actual, marcado por la digitalización de la experiencia urbana, la universalización de la orientación a partir de la integración de la tecnología GPS de los teléfonos inteligentes lleva a que sean las propias prácticas espaciales las que son colonizadas y anuladas en su posibilidad de generar creativa y libremente cursos de acción nuevos. Este tipo de affordances habría cooptado lo que, para Lefebvre -en el espíritu contracultural de 1968 -, era el impulso de resistencia a la tendencia uniformadora del espacio abstracto: la generación inmanente de espacios diferenciales (Soja, 1989: 35). A través de las dinámicas de interactividad que permiten los mapas en la web, el «derecho a la diferencia» que reclamaba Lefebvre (2013: 122) se incorpora a la producción misma de las representaciones del espacio. 


\section{LA PRODUCCIÓN DEL ESPACIO URBANO EN LA MODERNIDAD}

El apartado anterior ha sido dedicado al análisis de la propuesta conceptual de Henri Lefebvre para entender la producción del espacio. La tesis de principal interés para el presente artículo es que la alienación de la vivencia inmanente de la ciudad se produce cuando la representación del espacio $-\mathrm{o}$ espacio concebido- se superpone y anula las prácticas espaciales — espacio vivido-. El resultado, en términos de Lefebvre, es el predominio de un espacio abstracto, cuyas causas motoras y finales son ajenas a las necesidades de la vida individual y social. A partir de este acervo conceptual, el presente apartado estudiará dos modelos de explicación de la génesis del espacio abstracto que configuran la morfología de la ciudad contemporánea. Aunque alienada, la experiencia subjetiva de ese espacio abstracto permite aun un margen de autonomía, sea por disconformidad o a través de una experiencia estética activa, como fue la promulgada por Charles Beaudelaire en torno a la figura del flâneur.

\subsection{Orden y vigilancia: la creación de la ciudad-archivo}

La genealogía del poder-saber trabajada por Michel Foucault aporta una valiosa interpretación de la ciudad moderna como dispositivo de inteligibilidad de la población. La tesis subyacente a la obra de Foucault, como resulta bien conocido, es que toda forma de saber entraña una relación de poder, que es encarnada por los sujetos no como una constricción, sino como parte activa en la construcción de su subjetividad.

Con relación a la ciudad, la tesis de Foucault es que su transformación moderna es una consecuencia de su comprensión como un organismo patológico que es necesario sanar mediante técnicas médicas específicas (Foucault, 2001). Foucault no adopta retrospectivamente un enfoque urbanista. De sus escritos sobre «medicina urbana» se desprende, al contrario, que la ciudad como objeto de saber y reforma es creada a partir de su consideración como objeto de sanación. A partir del saber médico sobre la ciudad y del intento de prevenir y curar sus patologías, nacen formas paradigmáticas del poder que se aplicarán después a otros ámbitos espaciales e institucionales. Así, el poder disciplinario está íntimamente relacionado con el diseño de una tecnología de gobierno para la ciudad apestada. En el «modelo de la lepra», la solución a la enfermedad consistía en expulsar al cuerpo enfermo extramuros, de lo cual se deducía un ideal de purificación (Foucault, 2008a: 212). La especificidad del «modelo de la peste», por su parte, radica en que el ideal político coincide con 
el conjunto de prácticas implementadas para controlar y erradicar la enfermedad. El ideal político no consiste en el resultado de ese plan, sino en el estado de vigilancia, encauzamiento y disciplina que se da durante la presencia de la enfermedad y en la implementación del conjunto de prácticas de prevención y control de su transmisión (Foucault, 2008b: 230-231).

Para lograr responder a ese ideal de legibilidad, el principio rector de la reforma del espacio urbano que se acomete a partir del siglo XVII es la división:

a cada individuo, su lugar, y en cada emplazamiento, un individuo. [...] El espacio disciplinario tiende a dividirse en tantas parcelas como cuerpos o elementos haya que repartir. Es preciso anular los efectos de las distribuciones indecisas, la desaparición incontrolada de los individuos, su circulación difusa, su coagulación inutilizable y peligrosa (Foucault, 2008b: 233).

Esta «concepción analítica del espacio», en términos del propio Foucault, es el resultado de una planificación deliberada del espacio. No forma parte de los objetivos de esta investigación explorar los hitos históricos de esta planificación histórica del espacio urbano, pero dado que la ciudad de París es la principal referencia para la filosofía del espacio urbano con la que dialoga este artículo, resulta pertinente emplear como ejemplo paradigmático la Mémoire sur la réformation de la police de France, publicada en 1749 por François-Jacques Guillotte. El moto que preside la portada original de la obra es divide et impera. La aplicación de este precepto militar a la reforma policial alude no solo al gobierno del pueblo, sino a la posibilidad de conocerlo mejor (Birignani, 2013). La Mémoire..., no en vano, es un inventario de reformas sobre el espacio para facilitar la labor de vigilancia e identificación, esenciales para la prevención tanto del contagio de patologías como del desarrollo de prácticas delictivas: se promulgaba la división de bloques en máximos de 20 casas, las placas con nombre de las calles y del distrito al que estaban asignadas, la numeración de casas y de portales y la obligatoriedad de la identificación personal. Foucault relaciona estas pautas de legibilidad del espacio con la generalización de la revista como práctica de saber-poder.

El examen de la ciudad apestada requería un registro documental para el cual se creaban «códigos de individualidad disciplinaria que permiten transcribir, homogeneizándolos, los rasgos individuales establecidos por el examen» (Foucault, 2008b: 328). El responsable de cada barrio debía reportar la información recogida por los inspectores al alcalde de la ciudad: la vigilancia gene- 
ralizada, por tanto, generaba un sistema centralizado de información. La propia Mémoire... de Guillote defiende que

el primer Magistrado de la ciudad conocerá a todos los habitantes, su nombre, su procedencia, su condición, la fecha de su llegada a la ciudad, cuánto tiempo durará su estancia, su domicilio en cada barrio, calle, distrito [...] Conocerá más cosas de cada uno de ellos que el vecino de cada cual, con el que en cambio se cruzan cotidianamente» (citado por Birignani, 2013: 59).

La ciudad, en suma, es reformada para poder ser leída.

\subsection{La ciudad como circulación y espectáculo}

La concepción médica de la ciudad no termina con el problema de la peste. En su curso del Collège de France de 1978, titulado Seguridad, territorio y población, Foucault estudia cómo la gestión de la viruela o el cólera requerían un modelo de saber-poder diferente al poder disciplinario. Su tesis es que la nueva proyección médica sobre la ciudad se basa en la circulación libre (de aire, de población, de mercancías y de capital) como condición de posibilidad de la salud (Foucault, 2008a: 270). Coincide en la misma línea de análisis Richard Sennett, quien defiende que el descubrimiento de la circulación sanguínea ${ }^{2}$ sirvió como referencia metonímica para un nuevo paradigma de gobierno en la ciudad, pero también en la economía (Sennett, 2007: 151; 2019: 56). La gestión urbana de la viruela y el cólera pasaban por abrir espacios para que circulase el aire y para que el agua no se estancase. Del mismo modo, en el capitalismo incipiente teorizado por Adam Smith, la circulación de bienes y dinero es un síntoma de salud, frente al estancamiento rentista de la posesión fija y estable. Según conjetura Foucault, el modelo de gubernamentalidad que corresponde a este paradigma es la autorregulación, que no trata de marcar y fijar el territorio, ni impedir la circulación interna sino, al contrario

dejar fluir las circulaciones, controlarlas, seleccionar las buenas y las malas, permitir que la cosa se mueva siempre, se desplace sin cesar, vaya perpetuamente de un punto a otro, pero de manera tal que los peligros inherentes a esa circulación queden anulados (Foucault, 2008a: 271).

Cuyo principal hito fue la publicación en 1626 de la Exercitatio Anatomica de Motu Cordis et Sanguinis in Animalibus, de William Harvey. 
Ese paradigma circulatorio tuvo su reflejo en la revolución urbana de $\mathrm{Pa}$ rís diseñada por el barón Haussmann durante el Segundo Imperio. Si la patología se identifica con el agua estancada, los coágulos de aire y las barricadas levantadas por los trabajadores de París durante la revolución de 1848 , la solución pasaba por un rediseño del núcleo urbano cuyo principio fuera dejar pasar. Pese a su finalidad políticamente conservadora, la intervención de Haussmann supuso una plasmación espacial de la concepción revolucionaria del cambio. Lejos de limitarse a la reforma, derribó barrios enteros del centro para imponer su criterio de anchura para calles y avenidas y generar ejes principales de circulación. Las calles fueron retranqueadas y las fachadas fueron diseñadas para guardar una simetría escenográfica.

Las consecuencias de esta reforma urbana sobre las prácticas espaciales del París decimonónico han sido tematizadas por Richard Sennett en estudio sobre la separación de la ville y la cité, fenómenos que para este autor constituyen un rasgo definitorio de la modernidad industrial. ${ }^{3}$ El efecto principal de la planificación de Haussmann, que tanto Sennett como Harvey toman como paradigma de la experiencia en la modernidad (Harvey, 20o8b), fue que la red viaria convirtió la calle en un medio de escapar del centro urbano, más que de habitar en él: «la ciudad de Haussmann favorecía el espacio por encima del lugar; las redes de transporte conectaban la población a través del espacio, pero reducían su experiencia de lugar» (Sennett, 2019: 67). Son testimonio crítico de esta ruptura radical con la continuidad histórica las caricaturas de Daumier, contemporáneas de la reforma de Haussmann, que reflejan viandantes arrojados al tráfico frenético de los carruajes o la tragedia de vidas populares desposeídas de sus viviendas (Puelles, 2015: 344). Como también lo son la mezcla de nostalgia y fascinación de Charles Baudelaire en El pintor de la vida moderna o el relato de Balzac sobre el nacimiento de los grandes almacenes en El paraíso de las damas.

Consecuencia de esta reforma fue que París se convirtió en la ciudad de la luz, un gran centro de consumo, turismo y placer atraído por los cafés, los grandes almacenes, la industria de la moda y las grandes exposiciones (Harvey,

\footnotetext{
Para Sennett, ville equivale al espacio de la ciudad, objeto de las reformas de los urbanistas. Con cité, en cambio, alude a la ciudadanía, entendida como el modo de habitar el espacio urbano. Todo el análisis de Sennett se centra en evidenciar cómo los intentos de condicionar la cité a través de la planificación de la ville tuvieron como consecuencia un hiato entre ambas esferas, con consecuencias alienantes para la experiencia del espacio. Este par conceptual equivale al dualismo entre representación del espacio y prácticas espaciales que aquí estamos usando a partir del léxico de Henri Lefebvre.
} 
20o8b). Un rediseño de la ciudad no solo morfológico sino también funcional, que redundó en la expulsión de las clases obreras a la periferia.

La concepción médica del espacio estudiada por Foucault y Sennett no es una explicación suficiente de este cambio de paradigma urbano. Desde una perspectiva marxista basada en los Grundisse y en el volumen I de El Capital, tanto David Harvey (2013) como antes el propio Henri Lefebvre (2013: 102) coinciden en señalar como causa la necesidad capitalista de reubicar el excedente de una actividad productiva cuando acaece una crisis debida a barreras que impiden la continuidad del crecimiento exponencial de la plusvalía. Cuando baja el grado de plusvalía global producida por la industria, crece el grado de plusvalía formada a través de construcción inmobiliaria. El objetivo del urbanismo, en esa línea de argumentación, es «fijar el capital en el espacio» (Lefebvre, 2013: 112), lo cual se torna en un problema cuando el «segundo circuito del capital» pasa de ser coyuntural a convertirse en la fuente principal de plusvalor.

Según Harvey (2008b), Haussmann comprendió que su misión era contribuir a resolver el problema de la existencia de capital excedente y la situación de desempleo existente mediante la urbanización. A través del recurso al crédito, Haussmann ayudó, de hecho, a resolver el problema de la utilización del excedente de capital estableciendo un sistema protokeynesiano de mejoras urbanas en infraestructuras financiadas mediante el endeudamiento. Tras la segunda guerra mundial, y ante la necesidad de colocar el excedente generado por la industria bélica, Robert Moses proyectó en Nueva York lo que Haussmann había realizado en París. Mediante un sistema de autopistas y transformaciones de infraestructuras, suburbanización y remodelación total no solo de la ciudad sino del conjunto de la región metropolitana, contribuyó a resolver el problema de la absorción de capital excedente. Aunque su proyecto estrella de atravesar Manhattan con arterias circulatorias fue frenado gracias al impulso de Jane Jacobs, la activista y principal defensora de las «prácticas espaciales» de los barrios, el modelo de Moses se consolidó como el principal modo de recolocar el excedente industrial.

La suburbanización de Estados Unidos no fue únicamente cuestión de nuevas infraestructuras. Como en el Segundo Imperio, implicó una transformación radical de los estilos de vida y la introducción de nuevos productos. $\mathrm{Si}$ el espacio haussmaniano tuvo como correspondencia el estilo de vida y las prácticas espaciales de la burguesía urbana, la exportación de la concepción del espacio de Moses a todo el territorio estadounidense fue la condición especial de posibilidad del American way of life: la felicidad a través de la propiedad 
en un distrito periurbano, de electrodomésticos publicitados en la incipiente televisión y a través de la publicidad dirigida específicamente a las mujeres, de los dos coches en el garaje y el consecuente incremento en el consumo de petróleo (Harvey, 2008a). En el Estados Unidos de los treinta gloriosos, este proyecto absorbió con éxito el excedente y aseguró la estabilidad social, aunque a costa de vaciar los centros de los cascos urbanos y generar descontento entre aquellos, básicamente afroamericanos, a quienes se les negaba el acceso a la nueva prosperidad.

2.3 ¿Es posible la experiencia estética en el espacio abstracto de la ciudad contemporánea?

En la ciudad moderna, el espacio urbano es transparente a sí mismo, absolutamente legible, documentable y controlable. La ciudad industrial, por su parte, se torna espectacular y transitable, adquiriendo además un valor simbólico nuevo acorde a las pretensiones de reconocimiento de la burguesía industrial: el espacio urbano del nuevo centro de París se convierte en un espacio de representación que condiciona las prácticas espaciales que se pueden desarrollar en su seno. La espacialidad de la metrópolis moderna, por lo tanto, es un reflejo de la necesidad de gobernar a la población — para controlar, como se ha señalado, las epidemias-y de facilitar la circulación y el despliegue de la clase económicamente dominante. Por lo tanto, es un espacio abstracto que no responde a las necesidades particulares de sus habitantes. Se trata de un espacio objetivo, predefinido, legible e identificable, que reduce el margen de participación del sujeto individual en su configuración simbólica como en sus hábitos de uso.

En este punto, cabe recordar que este artículo conjetura la neutralización de la capacidad de reinterpretar subjetivamente el espacio abstracto de la ciudad, sobre todo cuando la representación del espacio - mediante mapas, planos y guías - se impone sobre las prácticas del espacio. Esa reinterpretación subjetiva de un espacio alienante tuvo a su principal teórico a finales del siglo XIX en Charles Baudelaire. Baudelaire escribe en el trauma de la revolución espacial de Haussmann. Nostálgico de los callejones oscuros que permitían el secreto de la vida bohemia, crítico con esa ciudad de la luz iluminada por las novedosas farolas de gas, Baudelaire quedó al mismo tiempo fascinado por la invasión del espacio público por la vida privada en los escaparates de los pasajes y de los grandes almacenes, por la moda y por la subsunción del individuo 
en las masas de paseantes urbanos (Cuesta Abad, 2014). A través de la figura del flâneur, Baudelaire defiende la posibilidad de una agencia estética en el espacio abstracto de la ciudad. Aunque alienante, para el paseante solitario todavía es posible captar la belleza fugaz y construir una experiencia estética en el ritmo frenético y normalizado de una ciudad erigida para la circulación funcional y no para la contemplación estética detenida. Concretamente, Baudelaire lo define como «un caleidoscopio dotado de conciencia», para significar esa capacidad para sintetizar de manera activa la experiencia fragmentaria del espacio urbano en el París del alto capitalismo (Cuesta Abad, 2014: 19-20), que también teorizaría Benjamin con las metáforas del montaje cinematográfico o del trapero (Benjamin, 2013: 4).

En Baudelaire, por tanto, hay un reducto de optimismo que no encontramos en otras reflexiones modernistas sobre la experiencia urbana. Para Georg Simmel, la discontinuidad, la aglomeración de impresiones inesperadas y de imágenes cambiantes, así como la presencia constante de las esferas económica, social y personal, saturan los sentidos y la mente e impiden la contemplación reflexiva (Simmel, 2005). Por ello, para Simmel la vida psíquica en la metrópolis tiene un carácter intelectualista. Con ello, el sociólogo alemán quería indicar que, ante la imposibilidad de regirse por la experiencia sensible, la orientación en el espacio urbano obedece a los esquemas de la representación del espacio o espacio concebido. En su interpretación, ello se observa principalmente en la generalización de la economía y del cálculo monetario como lógica de la vida mental de la polis y en la adecuación de los ritmos y del movimiento a la abstracción de los horarios (Simmel, 2005: 2-3).

En un contexto contemporáneo, Richard Sennett actualiza esta reflexión en referencia al espacio periurbano propio del paradigma que en el subapartado anterior ha sido atribuido a la influencia de Robert Moses en el urbanismo norteamericano:

El espacio se ha convertido en un medio para el movimiento puro - ahora clasificamos los espacios urbanos en función de lo fácil que sea atravesarlos o salir de ellos. [...] Navegar por la geografía de la sociedad contemporánea exige muy poco esfuerzo físico y, por tanto, participación. [...] El cuerpo se mueve pasivamente, desensibilizado en el espacio, hacia destinos situados en una geografía fragmentada y discontinua (Sennett, 2007: 20).

Aunque con causas distintas, el diagnóstico de Sennett es similar al de Simmel: la ciudad contemporánea desensibiliza, sustituyendo la experiencia subjetiva por la codificación objetiva del espacio. Sennett añade un símil útil 
para la hipótesis de trabajo de este artículo: «el viajero, como el espectador de televisión, experimenta el mundo en términos narcóticos» (Sennett, 2007: 21). La analogía con los medios de masas es interesante porque, en la actualidad, requeriría una lectura diferente: el paradigma comunicativo actual ya no es el de la unilateralidad, sino el de la interactividad, gracias a un receptor activo a través de las redes sociales, la valoración de la experiencia y la participación en procesos y votaciones.

No en vano, esa visión de un sujeto narcotizado por el exceso de estímulos de la ciudad ha sido contestada por los diagnósticos de Harmut Rosa y ByungChul Han acerca de la cultura tardomoderna. Para ambos, la forma específica de la alienación en nuestro presente no tiene que ver con una condición pasiva sino, al contrario, con un exceso de actividad. Hartmut Rosa entiende que la aceleración de las estructuras temporales de la modernidad tiene como efecto la obligación autoimpuesta de acometer más episodios de vida o experiencia en cada unidad de tiempo (Rosa, 2016: 31), mientras que Han sostiene que el imperativo de la multitarea conlleva que el síndrome del burn-out se convierta en la patología social paradigmática de la condición contemporánea (Han, 2017: 87).

¿Cómo podría concretarse esa forma específica de alienación en el contexto de la experiencia urbana? Los trabajos de Antonio Fernández Vicente suponen una aportación específica a esta cuestión. Su tesis es que la hiperconexión en red habilitada por el dispositivo smartphone intensifica tanto la profusión de estímulos propia de la experiencia urbana, como la privación sensorial de los ritmos acelerados (Fernández Vicente, 2019: 876). En la misma línea que Cerari, defiende que el caminar sería un modo de recuperar la lentitud y la intensidad propias de una experiencia auténtica, capaz de habilitar formas de encuentro y de conjurar la soledad que asola la vida en las grandes metrópolis (Fernández Vicente, 2019: 871).

La conjetura de este artículo, que será desarrollada de forma más específica en el apartado 4, es que, en la participación interactiva en la configuración de los mapas digitales a través de aplicaciones que comunican la posición y permiten valorar e ilustrar el espacio urbano, existe una forma específica de imposición de un espacio abstracto. No se tratará solamente de una hiperactividad nociva, tal como sostienen Han, Rosa o Fernández Vicente, sino que en esa apariencia de autonomía subjetiva se esconde una forma de heteronomía mediada por los dispositivos inteligentes y el uso de datos de sus aplicaciones. Antes de acometer este análisis, será necesario aclarar la consideración epis- 
temológica y pragmática del mapa, a través de un sucinto repaso de la revisión teórica sobre su estudio.

\section{REPRESENTACIÓN DEL ESPACIO: PARADIGMAS DEL MAPA}

Los mapas son artefactos simbólicos y representacionales que, en cuanto tales, inauguran posibilidades de acción. Ofrecen un marco para pensar el espacio, pero en su misma representación ya son un conjunto de enunciados acerca de ese mismo espacio.

La concepción más arraigada de los mapas es la representacional, basada en el ideal de racionalización del territorio. La premisa de que existe un espacio cartesiano, cuya representación debe prescindir de las contingencias propias de la experiencia subjetiva, alienta un imaginario del mapa como instrumento neutral, objetivo y de validez científica (Kitchin, Perkins y Dodge, 2009: 3). Desde esta perspectiva, los mapas son una herramienta epistemológica desvinculada de toda consideración ontológica o política: aspiran a ser documentos verdaderos, que representen el mundo tal cual es con un grado conocido de precisión, libre de carga valorativa alguna (Kitchin, Perkins y Dodge, 2009: 6).

A partir de la década de 1980, ante la presión intelectual de otras disciplinas que habían comenzado ya a asumir el giro discursivo impulsado por la filosofía posestructuralista, los mapas empiezan a entenderse como textos, discursos y prácticas. De una concepción neutra del mapa, se pasa a poner el acento en las relaciones de poder que pueden derivar de esa mediación representativa. La interpretación del mapa como un objeto cultural permite estudiar su recepción por parte del usuario, en lugar de ocuparse de evaluar la representación desde criterios abstractos aparentemente objetivos.

Desde un punto de vista explícitamente foucaultiano, Brian Harley recomienda estudiar el mapa atendiendo a los efectos de poder que busca implementar. En su opinión, la elaboración de un mapa no revela conocimiento, sino que lo crea (Harley, 1989). Y, en ese proceso de creación, las decisiones acerca de qué debe incluir la representación y cómo comunicarla introducen un gran componente de contingencia y subjetividad. Desde este punto de vista, los mapas son constructos sociales que, sin embargo, son tomados como neutrales porque reproducen un tipo de conocimiento formalizado que goza de un estatuto de privilegio epistémico en las sociedades ilustradas. Ha sido también señalado que los mapas contienen un «segundo texto» implícito 
(Wood, 1992), que introduce efectos de poder a través de un saber pretendidamente neutro.

El constructivismo social que aplica Harley busca revelar la política de representación implícita en los mapas. Pero este enfoque aun es presa del paradigma representativo, ya que postula la posibilidad de revelar la verdad que se esconde tras la representación (Kitchin, Perkins y Dodge, 2009: 11). En discusión explícita con Harley, Jeremy Crampton aboga por una lectura ontológica y no meramente óntica de los mapas, que en lugar de dar por supuesto que el espacio puede ser conocido y medido desde un criterio de objetividad, entienda los mapas como elementos en el espacio, que no lo revelan, sino que le dan lugar (Crampton, 2003). Desde ese punto de vista, la validez de los mapas no dependería de los criterios de cientificidad. Mapas alternativos como los artísticos o los experienciales tendrían el mismo fundamento de verdad (Pickles, 2004), pese a que, para que esta consideración sea efectiva, sería preciso neutralizar el efecto de autoridad de lo que Wood y Fels (2008) han llamado el «perimapa»: la calidad del papel y del diseño gráfico, la presentación y los criterios de la leyenda, entre otros elementos que condicionan la percepción de cientificidad.

Aunque la concepción del mapa por su recepción y efectos performativos sea diversa, lo más relevante para los fines de esta investigación es la disolución de la concepción dualista entre el autor y el lector, el diseño y el uso, la representación o la práctica. Como argumenta Corner (1999), siguiendo a Baudrillard, el territorio no precede al mapa y el mapa está en un estado constante de devenir. Ingold (200o) defiende una concepción narrativa del mapa, en el que el uso - la navegación - no suceda, sino que preceda o sea simultánea a la elaboración del mapa. Para evitar que la práctica espacial se reduzca al espacio concebido previamente desde un punto de vista imaginario y aparentemente objetivo, la teoría crítica de los mapas defiende que estos son prácticas independientes de su soporte material y su circulación comercial: todos somos productores usuarios de mapas en la cotidianeidad de nuestras vidas (Kitchin y Dodge, 2007: 5).

Esta es también la concepción del colectivo Skalter, promovido y teorizado por el arquitecto Francesco Careri. A través de sus deambuleos por la ciudad, esta iniciativa de intervención artística y urbanista descubre los espacios velados en las fronteras del caminar, aquellos que el movimiento Dada había denominado como banales y que los surrealistas definieron como el inconsciente de la ciudad (Careri, 2013: 28). Las prácticas del caminar ensayadas por este colectivo recrean un paisaje alternativo, en el que el recorrido (entendido a la 
vez como acto de atravesar, línea que atraviesa el espacio y estructura narrativa) revela espacios vacíos y genera una representación alternativa del espacio (walkscapes, en términos de Careri), en la que toman importancia espacios vacíos desde el punto de vista del espacio objetivo, pero significativos desde el punto de vista del habitar (Careri, 2013: 37).

\section{EL MAPA DIGITAL Y LA COLONIZACIÓN COMERCIAL DE LA EXPERIENCIA}

En el apartado 2 el análisis de la producción de un espacio abstracto de efectos desensorializadores terminaba con un interrogante: ipermite el consumo interactivo de mapas digitales invertir la pasividad forzosa del habitante de la ciudad? ¿Es el activismo digital a la hora de exhibir y valorar la experiencia una universalización del flâneur, en la medida en que todos los usuarios de aplicaciones como Google Maps tendrían la posibilidad de compartir su observación y experiencia estética de la ciudad?

En el apartado 3, por su parte, un sucinto recorrido de la teoría reciente acerca de los mapas permite concluir que la consideración representacional del mapa esconde relaciones de poder que deben ser sustituidas por una nueva legitimidad de los sujetos para mapear la ciudad a partir de su experiencia cotidiana.

Si vinculamos estas conclusiones, podríamos colegir que, en efecto, las aplicaciones de mapas que usan la geolocalización instantánea y permiten la publicación de experiencias personales y valoraciones serían una proyección tecnológica de ese mapeo subjetivo.

Google Maps es una aplicación que, a través de la navegación GPS, ofrece imágenes de mapas desplazables, condiciones de tráfico en tiempo real, diseños de rutas y fotografías por satélite del mundo. La opción de mapas desplazables permite una experiencia individualizada del espacio objetivo, ya que es el mapa el que se escapa a la posición del sujeto, en lugar de ser el sujeto el que busca interpretar el mapa para orientarse. El mapa, a su vez, ofrece información adicional en función del medio de desplazamiento: no solo acerca del tráfico y de la ruta más amplia, sino que también permite visualizar servicios cercanos y lugares de interés y acceder a la valoración y a las fotografías tomadas por otros usuarios. Intuitivamente, por tanto, parece que podríamos estar ante la democratización absoluta del mapa: adaptado a la situación, receptivo a la expresión de la experiencia, plegado a las necesidades del individuo y cola- 
borativo en la construcción de su información. A continuación, se considerarán dos posibles réplicas de esta optimista lectura.

Recientes investigaciones en el campo de las neurociencias sugieren que la actividad cerebral es menos activa cuando empleamos el GPS. En la experimentación reportada por Javadi et al. (2017), cuando un viandante entraba en una calle nueva, su hipocampo y el córtex prefrontal —áreas cerebrales encargadas de la orientación y la creación de mapas mentales, respectivamente- experimentaban picos de actividad. El hipocampo se encarga de simular el viaje según las posibles alternativas y el córtex prefrontal nos ayuda a saber cuál nos llevará a nuestro destino. La intensidad de estas zonas cerebrales aumentaba con el número de rutas disponibles, pero en cambio no se incrementaba lo más mínimo cuando usaban un GPS. Este hallazgo sugiere que la orientación mediante mapas digitales no fomentaría la vivencia activa del espacio urbano, sino que contribuiría a la desensorialización descrita en contextos diferentes por Richard Sennett y Georg Simmel.

En segundo lugar, la actual denuncia de los sesgos cognitivos y sociales que implementan los algoritmos de aprendizaje automático (O'Neil, 2018) debe prevenir de confundir aplicaciones como Google Maps con una tabla rasa para que el usuario inscriba y comparta su experiencia. La representación del espacio a través de aplicaciones como Google Maps se presenta como una mera proyección de la libre experiencia del sujeto, libre de los sesgos a los que obligaba la cartografía tradicional.

Sin embargo, la fenomenología del espacio a través de estas condiciones está sesgada por el análisis de nuestro rastro de datos y por su categorización en criterios comerciales explotados por compañías privadas. Lo que aparece en la cartografía posicional del individuo, por tanto, es un producto adaptado a sus características como consumidor, cuyo objetivo es encauzar sus deseos y su voluntad. Google Maps, en consecuencia, produce un espacio adaptado a la experiencia previa de cada individuo: el espacio objetivo de la ciudad se desrealiza, pero también se neutraliza la posibilidad de una vivencia libre y creativa del espacio. Esta representación del espacio adaptada al rastro de datos individual se aprovecha de la tendencia innata al mínimo esfuerzo cognitivo descubierta por Daniel Kaheman (2011). La especificidad de la economía de la atención consistiría en un aprovechamiento sistemático de nuestras heurísticas cognitivas (recursos rápidos mediante los que se organiza el cerebro, pero que en decisiones importante producen efectos de sesgo) por parte de los grandes centros de poder (Broncano, 2019: 139). Si la ciudad de los grandes bulevares parisinos es el correlato espacial de la burguesía industrial, el espacio 
digital adaptado a las preferencias individuales es el correlato de un capitalismo de la experiencia y la atención.

Esta tesis ha sido prefigurada por el Manifiesto Posfotográfico de Joan Fontcuberta (Fontcuberta, 2016). Aunque no explícitamente dedicado a la ciudad, Fontcuberta defiende la imposibilidad de hacer fotografías auténticamente nuevas, pues la experiencia subjetiva estaría ya irremediablemente intervenida por el imaginario socialmente distribuido. El movimiento posfotográfico, no en vano, propugna el reciclaje lúdico de fotografías en la nube, siendo muchos los ejemplos de intervenciones artísticas a partir de imágenes extraídas de Google Street View. La experiencia estética del flâneur ya no sería posible en la ciudad posfotográfica. Para Sontag,

la fotografía al principio se consolida como una extensión de la mirada del flâneur de clase media, cuya sensibilidad fue descrita tan atinadamente por Baudelaire. El fotógrafo es la versión armada del paseante solitario que explora, acecha, cruza el infierno urbano, el caminante voyeurista que descubre en la ciudad un paisaje de extremos voluptuosos (Sontag, 1996: 79).

Esa resistencia estética al espacio abstracto de la ciudad habría sido colonizada por el capitalismo de la experiencia, que emplea como combustible, precisamente, el afán de autenticidad y de expresividad de sus usuarios. Aunque de apariencia subjetiva, por lo tanto, la cartografía digital supondría la expansión del espacio objetivo hasta los reductos de la actividad neurológica y la creatividad humanas.

\section{CONCLUSIONES}

Este artículo ha tratado de analizar cómo la generalización de las tecnologías de geolocalización y su generalización a través de aplicaciones de mapas digitales modifica nuestra experiencia subjetiva del espacio urbano. A partir de los conceptos empleados por Henri Lefebvre para analizar la producción trialéctica del espacio urbano, de la revisión acerca de la reflexión teórica sobre la experiencia estética y sensorial del sujeto en la metrópolis contemporánea y de la consideración de los marcos interpretativos del mapa como artefacto cultural, se extraen las siguientes conclusiones:

- El entorno digital supone un nuevo «perimapa» (Wood y Fels, 2008) que dota de una autoridad seudocientífica a la orientación 
digital. La inscripción de la propia experiencia y opinión en este tipo de soportes online, por tanto, es percibida como neutral, libre de los sesgos realmente operativos en su configuración.

- La orientación adaptada a la posición y huella de datos individuales no supone una recuperación de la agencia subjetiva a la hora de configurar el espacio urbano: al contrario, supone una colonización de la conciencia subjetiva a través de la predeterminación de la experiencia. En ese sentido, es una metamorfosis del espacio urbano acorde a las condiciones del capitalismo de la experiencia.

- Debido a esto, la relación del sujeto con el espacio urbano no coincide ya con esa narcotización de la experiencia propia de las reformas que primaron el desplazamiento al habitar, tal como diagnosticaron los teóricos de la metrópolis modernista y, más cerca de nuestro presente, el diagnóstico de Sennett sobre la separación de ville y cité o la genealogía de Antonio Fernández Vicente sobre la imposibilidad del caminar en la era del smartphone. El sujeto no experimenta la ciudad de modo pasivo, sino hiperactivo. Esa hiperactividad, no obstante, se encuentra sesgada por formas de poder heterónomas que le alienan objetivamente pese a la apariencia subjetiva de autonomía y autenticidad de su experiencia.

- La cartografía digital interactiva no es una oportunidad para una revisión de la idea representacional del mapa. Bajo la apariencia de subjetividad, esta percepción del espacio sigue estando subordinada a un espacio abstracto producido por dinámicas ajenas a las necesidades del ciudadano. La producción digital del espacio, por tanto, no es por sí misma una herramienta para ejercer el derecho a la ciudad.

\section{BIBLIOGRAFÍA}

Baringo Ezquerra, David (2013). La tesis de la producción del espacio en Henri Lefebvre y sus críticos: un enfoque a tomar en consideración. Quid 16. Revista del área de Estudios Urbanos, 3, 119135 .

Benjamin, W. (2013). Obra de los pasajes, V.1. Madrid: Abada. 
Birignani, Cesare (2013). The Police and the City, 1660-1750. Tesis doctoral. New York City: Columbia University.

Broncano, Fernando (2008). In media res: Cultura material y artefactos. ArtefaCToS, 1(1), 18-32.

Broncano, Fernando (2009). La melancolía del ciborg. Barcelona: Herder.

Broncano, Fernando (2010). Cognición, tecnología y racionalidad. Revista CS, 6, 397-411. https://doi.org/10.18046/recs.i6.474

Broncano, Fernando (2012). Humanismo cyborg. A favor de unas nuevas humanidades más allá de los límites disciplinares. Revista Educación y Pedagogía, 24(62), 103-116.

Broncano, Fernando (2019). Puntos ciegos. Ignorancia pública y conocimiento privado. Madrid: Lengua de Trapo.

Careri, Francesco (2013). Walkscapes. Andar como práctica estética. Barcelona: Gustavo Gili.

Corner, J. (1999). The agency of mapping: speculation, critique and invention. En Cosgrove, D. (ed.). Mapping. London: Reaktion.

Crampton, Jeremy W. (2003). Cartographic Rationality and the Politics of Geosurveillance and Security. Cartography and Geographic Information Science, 30(2), 135-148.

Cuesta Abad, J.M. (2014). Estudio introductorio. En Benjamin, Walter. Baudelaire. Madrid: Abada.

De Azúa, Félix (2015). La invención de Caín. Sobre las ciudades. Madrid: Debate.

De Certeau, Michel (2007). La invención de lo cotidiano 1. Artes de hacer. México: Iberoamericana.

Dear, Michael (1994). Les aspects postmodernes de Henri Lefebre. Espaces et societés, 2(76), 31-40.

Debord, Guy (2010). La sociedad del espectáculo. Valencia: Pre-Textos.

Dimendberg, Edward (1998). Henir Lefebvre on abstract space. En Light, A. y Smith, J.M. (eds.). The Production of Public Space (17-46). Boston: Roman and Littleflield. 
Fernández Vicente, Antonio (2019). Caminar en la era del smartphone. Revista Mexicana de Sociología 81, 4, 855-880.

Fontcuberta, Joan (2016). La furia de las imágenes. Notas sobre la postfotografía. Madrid: Galaxia Gutenberg.

Foucault, Michel (2001). Naissance de la médecine sociale. En Dits et écrits II, 1976-1978 (207-228). Paris: Gallimard.

Foucault, Michel (2008a). Seguridad, territorio y población. Curso del Collége de France (1977-1978). Tres Cantos: Akal.

Foucault, Michel (2008b). Vigilar y Castigar. Nacimiento de la prisión. Buenos Aires: Siglo XXI.

Goonewardena, Kanishka (2011). Henri Lefebvre. En Ritzer, George y Stepnisky, Jeffrey (eds.). Wiley-Blackwell Companion to Contemporary Social Theory (44-71). London: Wiley-Blackwell.

Guillaute, François-Jacques (1974). Mémoire sur la réformation de la pólice de France. Paris : Hermann.

Han, Byung-Chul (2017). La Sociedad del cansancio. Barcelona: Herder.

Harley, J.B. (1989). Deconstructing the map. Cartographica, 26(2), 1-20.

Harvey, David (2008a). El derecho a la ciudad. New Left Review, 53, 2339 .

Harvey, David (2008b) París, capital de la modernidad. Tres Cantos: Akal.

Harvey, David (2013) Ciudades rebeldes. Del derecho a la ciudad a la revolución urbana. Tres Cantos: Akal.

Ingold, T. (2000). The Perception of the Environment: Essays in Livelihood, Dwelling and Skill. London: Routledge.

Javadi, A-H. et al. (2017). Hippocampal and prefrontal processing of network topology to simulate the future. Nature Communications, 8.

Kaheman, Daniel (2011). Pensar rápido, pensar despacio. Madrid: Debate. Kitchin, Rob y Dodge, Martin (2007). Rethinking maps. Progress in Human Geography, 31(3), 331-344. 
Kitchin, Rob, Perkins, Chris y Dodge, Martin (2009). Thinking about maps. En Kitchin, Rob, Perkins, Chris y Dodge, Martin. Rethinking Maps (1-25). London: Routledge.

Lefebvre, Henri (1972). La revolución urbana. Madrid: Alianza.

Lefebvre, Henri (1980). La vida cotidiana en el mundo moderno. Madrid: Alianza.

Lefebvre, Henri (2013). La producción del espacio. Madrid: Capitán Swing.

O’Neil, C. (2018). Armas de destrucción matemática. Cómo el big data aumenta la desigualdad y amenaza la democracia. Madrid: Capitán Swing.

Pew Research Center (2019). Smartphone ownership is growing around the world. Recuperado de: https://www.pewglobal.org/2019/o2/05/smartphone-ownership-isgrowing-rapidly-around-the-world-but-not-always-equally/

[Consultado el zo de abril de 2019].

Pickles, John (2004). A History of Spaces: Cartographic Reason, Mapping and the Geo-Coded World. London: Routledge.

Puelles, Luis (2015). Honoré Daumier: la risa republicana. Madrid: Abada. Rosa, Harmut (2016). Alienación y aceleración. Hacia una teoría crítica de la temporalidad en la modernidad tardía. Buenos Aires: Katz.

Schmid, Christian (2008). Henri Lefebvre's Theory of the Production of Space. En Goonerwardena, Kanishka et al. (eds). Space, Difference, Everyday Life: Reading Henri Lefebvre. New York: Routledge.

Sennett, Richard (2007). Carne y piedra. El cuerpo y la ciudad en la civilización occidental. Madrid: Alianza.

Sennett, Richard (2019). Construir y habitar. Ética para la ciudad. Barcelona: Anagrama.

Simmel, George (2005). La metrópolis y la vida mental. Bifurcaciones: revista de estudios culturales urbanos, 4 .

Soja, Edward E. (1989). Postmodern Geographies: The Reassertion of Space in Critical Social Theory. London: Verso Press. 
Sontag, Susan (1996). Sobre la fotografía. Madrid: Alfaguara.

Virilio, Paul (1997). Un paisaje de acontecimientos. Buenos Aires: Paidós. Torres-Albero, Cristóbal (2005). El cambio de las sociedades y el papel de la tecnociencia. Un cauto balance de vinculación. En Ariño, Antonio (coord.). Las encrucijadas de la diversidad cultural (159-176). Madrid: Centro de Investigaciones Sociológicas.

Wood, Denis (1992). The Power of Maps. New York: Guilford Press.

Wood, Denis y Fels, John (2008). The Nature of Maps: Cartographic Constructions of the Natural World. Chicago: University of Chicago Press. 